\title{
Asymmetric Dimethylarginine Level as an Indicator for Cardiovascular Risk in Patients with Metabolic Syndrome
}

\author{
(D) Serdar Arıcı1 ${ }^{1}$, (D) Ayşegül Kapuci², (D) Sinem Kıyıci³, (D) Gürcan Kısakol³ \\ 1 University of Health Sciences Turkey, Prof. Dr. Cemil Taşşıoğlu City Hospital, Clinic of Medical Oncology, İstanbul, Turkey \\ 2Bursa City Hospital, Clinic of Internal Medicine, Bursa, Turkey \\ 3University of Health Sciences Turkey, Bursa Yüksek Ihtisas Training and Research Hospital, Clinic of Endocrinology and Metabolism, Bursa, Turkey
}

\section{Abstract}

Objective: This study aimed to make an early diagnosis of endothelial dysfunction, the initial pathology of atherosclerosis in metabolic syndrome (MS) patients, and to investigate the usefulness of serum asymmetric dimethylarginine (ADMA) levels as a marker of cardiovascular risk.

Methods: Thirty-eight patients (24 women and 14 men) who were diagnosed with MS, according to the National Cholesterol Education Program Adult Treatment Panel III, were included in the study. Patients with a history of systemic diseases, except components of MS, and smokers were excluded from the study. The control group comprised 25 and 12 healthy women and men, respectively; with similar age profiles. Serum ADMA levels and carotid intima-media thickness (CIMT) were measured in patients and controls.

Results: Lower serum ADMA levels and higher CIMT measurements were observed in the patient group than in the control group ( $p<0.001$ and $p<0.001$, respectively). C-reactive protein (CRP) was significantly higher in patients than in controls $(p<0.001)$. Correlation analysis revealed a significant and inverse correlation between plasma ADMA concentrations and fasting blood glucose $(p<0.001, r=-0.421)$, HbA1C $(p=0.001, r=-0.361), C R P(p=0.003, r=-0.335)$, and CIMT measurements ( $p=0.024, r=-0.261)$. Among the patients with MS, 32 were diagnosed with type $2 \mathrm{DM}$; among whom 29 were receiving metformin treatment. ADMA levels in MS patients with and without metformin therapy were $4.5 \pm 1.7 \mathrm{nmol} / \mathrm{mL}$ and $7.3 \pm 1.2 \mathrm{nmol} / \mathrm{mL}$, respectively; and the ADMA levels were significantly lower in the former than in the latter $(p=0.007)$.

Conclusion: MS is a cluster of diseases in which pro-atherosclerotic processes such as DM, hypertension, obesity, and hypercholesterolemia coexist. In our study, when increased CIMT values were considered as evidence for the presence of atherosclerosis in patients, the low serum ADMA levels may be related to metformin therapy, poor glycemic control, and/or problems in the immune-assay.

Keywords: Metabolic syndrome, ADMA, CIMT, atherosclerosis

\section{INTRODUCTION}

Significant features of metabolic syndrome (MS) include central obesity, hypertension, dyslipidemia, glucose intolerance, vascular inflammation, and prothrombotic condition (1). Studies have highlighted the effect of insulin resistance on MS components and its critical role in the pathophysiology of MS (2). Insulin resistance may lead to hypertension, dyslipidemia, coagulation abnormality, endothelial dysfunction, and cardiovascular diseases (1).

Endothelial dysfunction is the earliest evidence of coronary artery disease and its occurrence in the early stages of the disease; before atheroma plaque formation. The main indicator of endothelial dysfunction is the disruption of endotheliumdependent vasodilatation caused by nitric oxide (NO). NO 
is synthesized from L-arginine by NO synthase (NOS). NO produced in the endothelium, affects vascular tone and leads to vasodilatation $(3,4)$.

L-arginine is methylated with intracellular methyltransferases and converted to asymmetric dimethylarginine (ADMA), the metabolite of methylated L-arginine. Since, ADMA is an endogenous competitive inhibitor of NOS; it is an important risk predictor for cardiovascular disease; as a marker of endothelial dysfunction (5).

Studies have revealed that in sudden deaths secondary to coronary artery disease, the development of atherosclerosis was not limited to the coronary arteries alone. Therefore, ultrasonographically measured carotid intima-media thickness (CIMT) may be used to detect the presence of atherosclerotic plaques, degree of calcification, arterial lumen diameters, and asymptomatic atherosclerotic disease (6).

In this study, endothelial dysfunction and increased cardiovascular risk in MS were evaluated with serum ADMA levels and CIMT that are considered to be risk factors for cardiovascular disease. The aim of this study was to make an early diagnosis of endothelial dysfunction, the initial pathology of atherosclerosis in MS patients, and to investigate the usefulness of serum ADMA levels as a marker of cardiovascular risk.

\section{METHODS}

\section{Study Population}

This study was performed prospectively in patients followed in internal medicine, and/or endocrinology and metabolism disease clinics of Bursa Yüksek Ihtisas Training and Research Hospital from which the ethics committee approval is obtained (23.10.2013/3). For the diagnosis of MS, according to the National Cholesterol Education Program Adult Treatment Panel III criteria, at least three of the following criteria were required:

- Fasting blood glucose (FBG) $>110 \mathrm{mg} / \mathrm{dL}$

- Triglyceride (TG) $>150 \mathrm{mg} / \mathrm{dL}$

- Waist circumference $>88 \mathrm{~cm}$ for women, $>102 \mathrm{~cm}$ for men

- High-density lipoprotein (HDL) cholesterol $<50 \mathrm{mg} / \mathrm{dL}$ in women and $<40 \mathrm{mg} / \mathrm{dL}$ in men

- Blood pressure $>130 / 85 \mathrm{mmHg}$

Results of hematological investigations were obtained from the archived files of patients. Waist circumferences and body mass indices of patients (BMI) were calculated at the time of their inclusion in the study. ADMA and CIMT were assessed prospectively.

\section{Laboratory Methods}

Venous blood samples for serum ADMA level measurements were taken in the morning, following a 12-hour fasting period. They were transported to the laboratory in ice molds and centrifuged at $4000 \mathrm{rpm}$ for $5 \mathrm{~min}$ and stored at $-80{ }^{\circ} \mathrm{C}$. ADMA measurements were carried out with $A D$ double-antibody sandwich ELISA method with Human ADMA ELISA Kit (Sunred Biological Technology, Shanghai China), with a sensitivity range of $0.05-15 \mathrm{nmol} / \mathrm{mL}$, in the Biochemical Laboratory of Bursa Yüksek Ihtisas Training and Research Hospital.

\section{Carotid Intima-media Thickness}

CIMT measurements were performed for patient group and control group using Logiq 5 Pro (GE Healthcare, Milwaukee, USA) ultrasound, using a $7.5 \mathrm{MHz}$ linear array transducer. For CIMT, three measurements were taken from approximately 1 $\mathrm{cm}$ proximal to the bifurcation of both main carotid arteries, when the anterior and posterior walls were seen bilaterally. The arithmetic mean of the three measured values of the randomly selected region was used.

\section{Statistical Analysis}

Average, standard deviation, median, lowest, highest, frequency, and ratio values were used for descriptive statistics. The distribution of variables was assessed with the KolmogorovSmirnov test. Mann-Whitney $U$ test and independent sample $t$-test were used in the analysis of quantitative data, while $\chi^{2}$ test was used for qualitative data. Spearman correlation analysis was used for evaluating correlation. Statistical analysis of the data was performed with "SPSS for Windows, Version 22." The data were represented by mean \pm standard deviation, and $p<0.05$ was considered as statistically significant.

\section{RESULTS}

Thirty-eight patients with MS (24 women and 14 men) and 37 healthy controls ( 25 women and 12 men) were included in the study, with median ages of $45.1 \pm 8.3$ years (range; $30-59$ years) and $41.4 \pm 8.0$ years (range; 31-60 years), respectively. The median FBG and HbA1c levels were $167 \mathrm{mg} / \mathrm{dL}(96-280 \mathrm{mg} / \mathrm{dL})$ and $9 \%$

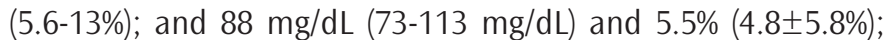
in MS and control groups, respectively. The median TG and HDL cholesterol levels were $269 \mathrm{mg} / \mathrm{dL}(115-480 \mathrm{mg} / \mathrm{dL})$ and $39 \mathrm{mg} /$ $\mathrm{dL}(22-63 \mathrm{mg} / \mathrm{dL})$; and $112 \mathrm{mg} / \mathrm{dL}(57-198 \mathrm{mg} / \mathrm{dL})$ and $45 \mathrm{mg} /$ $\mathrm{dL}(21-84 \mathrm{mg} / \mathrm{dL})$; in MS and control groups, respectively. The median waist circumferences in MS and control groups were 110 
$\mathrm{cm}(104-220 \mathrm{~cm})$ and $65 \mathrm{~cm}(60-78 \mathrm{~cm})$, respectively; while the median systolic and diastolic blood pressure (SBP and DBP) were $130 \mathrm{mmHg}(120-150 \mathrm{mmHg})$ and $80 \mathrm{mmHg}(75-90 \mathrm{mmHg})$ in the MS group and $120 \mathrm{mmHg}(100-128 \mathrm{mmHg})$ and $75 \mathrm{mmHg}(60-80$ $\mathrm{mmHg}$ ) in control group (Table 1).

The serum ADMA levels were significantly different between MS and control groups $(5.1 \pm 1.9 \mathrm{nmol} / \mathrm{mL}$ and $7.7 \pm 3.3 \mathrm{nmol} /$ $\mathrm{mL}$, respectively; $p<0.001)$. The same was true for CIMT measurements $(0.07 \pm 0.01 \mathrm{~mm}$ and $0.05 \pm 0.01 \mathrm{~mm}$, respectively; $\mathrm{p}<0.001$ ) (Table 2) (Figure 1, 2).

In MS group, statistically significant negative correlations were observed between serum ADMA levels and (BMI) $(r=-0.428$; $p=<0.001)$, waist circumference $(r=-0.351 ; p=0.002)$, SBP $(r=-$ $0.330 ; p=0.004), F B G(r=-0.421 ; p=<0.001), H b A 1 c(r=-0.361$; $p=0.001)$, TG $(r=-0.316 ; p=0.006), \operatorname{CRP}(r=-0.335 ; p=0.003)$, and CIMT ( $r=-0.261 ; p=0.024)$. There was a positive correlation between serum ADMA levels and HDL cholesterol $(r=0.247$; $\mathrm{p}=0.033$ ) (Table 3).

Further, statistically significant positive correlations were observed between CIMT values and BMI $(r=0.713 ; p=<0.001)$, waist circumference $(r=0.661 ; p=<0.001)$, SBP $(r=0.610$; $p=<0.001), \quad$ FBG $(r=0.711 ; p=<0.001), \quad H b A 1 C \quad(r=0.686$; $p=<0.001)$, TG $(r=0.502 ; p=<0.001)$, and CRP $(r=0.402$; $p=<0.001$ ). There was a negative correlation between CIMT values and HDL cholesterol $(r=-0.279 ; p=0.015)$ (Table 4).

Thirty-two of the patients with MS were diagnosed with type 2 DM, and 29 of these were receiving metformin treatment. ADMA levels in MS patients with and without metformin therapy were $4.5 \pm 1.7 \mathrm{nmol} / \mathrm{mL}$ and $7.3 \pm 1.2 \mathrm{nmol} / \mathrm{mL}$, respectively. ADMA levels were significantly lower in patients with MS receiving metformin than in patients without metformin $(p=0.007)$.

\begin{tabular}{|c|c|c|c|c|c|}
\hline \multirow[t]{2}{*}{ Variables } & \multicolumn{2}{|l|}{ MS group } & \multicolumn{2}{|c|}{ Control group } & \multirow[t]{2}{*}{$p$} \\
\hline & Mean \pm SD & Med (Min-Max) & Mean \pm SD & Med (Min-Max) & \\
\hline Age (years) & $45 \pm 8.3$ & $46(30-59)$ & $41.4 \pm 8.0$ & $42(31-60)$ & NS \\
\hline Weight (kg) & $101.6 \pm 12.8$ & $98(83-15)$ & $67.2 \pm 4.8$ & $65(60-80)$ & $<0.001$ \\
\hline BMI $\left(\mathrm{kg} / \mathrm{m}^{2}\right)$ & $36.6 \pm 4.2$ & $36(31-46)$ & $23.2 \pm 1.2$ & $24(20-25)$ & $<0.001$ \\
\hline Ws C. (cm) & $114.0 \pm 18.9$ & $110(104-220)$ & $66.8 \pm 4.9$ & 65 (60-78) & $<0.001$ \\
\hline SBP (mmHg) & $132.1 \pm 7.3$ & $130(120-150)$ & $116.4 \pm 6.8$ & $120(100-128)$ & $<0.001$ \\
\hline $\mathrm{DBP}(\mathrm{mmHg})$ & $82.5 \pm 4.8$ & $80(75-90)$ & $74.6 \pm 5.9$ & $75(60-80)$ & $<0.001$ \\
\hline FBG $(\mathrm{mg} / \mathrm{dL})$ & $165.8 \pm 50.1$ & $167(96-280)$ & $87.8 \pm 8.1$ & $88(73-113)$ & $<0.001$ \\
\hline BUN (mg/dL) & $13.8 \pm 3.6$ & $13(6.0-25.0)$ & $12.1 \pm 4$ & $12(5.0 \pm 24)$ & NS \\
\hline Creatinin (mg/dL) & $0.7 \pm 0.2$ & $0.7(0.1-1.0)$ & $0.8 \pm 0.1$ & 0.8 (0.6-1.0) & NS \\
\hline Tot C (mg/dL) & $227.4 \pm 43.7$ & $223(138-356)$ & $201.0 \pm 43.1$ & 199 (114-300) & 0.010 \\
\hline LDL-C (mg/dL) & $137.8 \pm 65.2$ & $130(51-450)$ & $124.8 \pm 36.5$ & $124(61-205)$ & NS \\
\hline HDL-C (mg/dL) & $39.1 \pm 8.8$ & $39(22-63)$ & $46.9 \pm 11.8$ & $45(21-84)$ & 0.001 \\
\hline TG (mg/dL) & $275.8 \pm 100$ & $269(115-480)$ & $136.5 \pm 74.6$ & 112 (57-198) & $<0.001$ \\
\hline AST (IU/L) & $25.4 \pm 12.9$ & $21(12-70)$ & $21.1 \pm 4.0$ & $12(5-24)$ & NS \\
\hline ALT (IU/L) & $26.7 \pm 13.5$ & $24(9-64)$ & $20.8 \pm 10.4$ & $17(8-45)$ & 0.036 \\
\hline Uric acid (mg/dL) & $4.8 \pm 1.0$ & $4.9(2.7-6.6)$ & $4.9 \pm 1.5$ & $4.8(2.2 \pm 7.5)$ & NS \\
\hline HbA1c (\%) & $8.7 \pm 2.1$ & $9(5.6-13)$ & $5.5 \pm 0.2$ & $5.5(4.8 \pm 5.8)$ & $<0.001$ \\
\hline CRP (mg/dL) & $8.1 \pm 5$ & $6.3(3.4-21)$ & $4.5 \pm 2$ & $3.4(3.3-11)$ & $<0.001$ \\
\hline
\end{tabular}

Table 2. Carotid intima media thickness and asymmetric dimethylarginine levels in metabolic syndrome and control groups

\begin{tabular}{|l|l|l|l|}
\hline & MS group (mean \pm SD) & Control group (mean \pm SD) & $\mathbf{p}$ \\
\hline CIMT $(\mathbf{m m})$ & $0.07 \pm 0.01$ & $0.05 \pm 0.01$ & $<0.001$ \\
\hline ADMA $(\mathbf{n m o l} / \mathbf{m L})$ & $5.1 \pm 1.9$ & $7.7 \pm 3.3$ & $<0.001$ \\
\hline SD: Standard deviation, CIMT: Carotid intima media thickness, ADMA: Asymmetric dimethylarginine & \\
\hline
\end{tabular}




\section{DISCUSSION}

In the present study, serum ADMA levels and CIMT measurements were compared between MS patients; a risk group for atherosclerosis, and healthy controls.

Some studies have focused on the relationship between serum ADMA levels and atherosclerosis. Vallance et al. (7) were the first to demonstrate that endogenous ADMA antagonizes endotheliuminduced vasodilatation. They reported elevated plasma ADMA levels in patients with endothelial dysfunction, and considered it as a risk factor for atherosclerosis. Böger et al. (8) described ADMA as a new cardiovascular risk factor and found that plasma ADMA levels were higher in patients with hypercholesterolemia than in

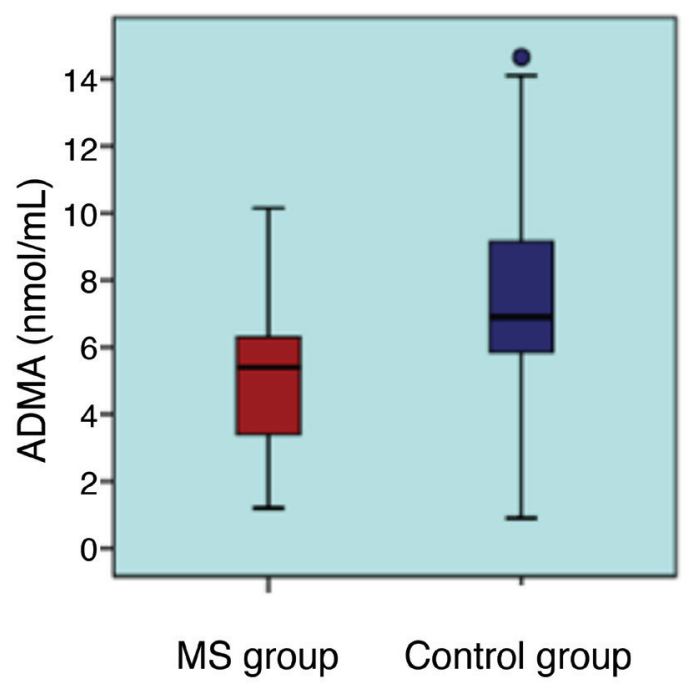

Figure 1. Serum asymmetric dimethylarginine levels ADMA: Asymmetric dimethylarginine, MS: Metabolic syndrome

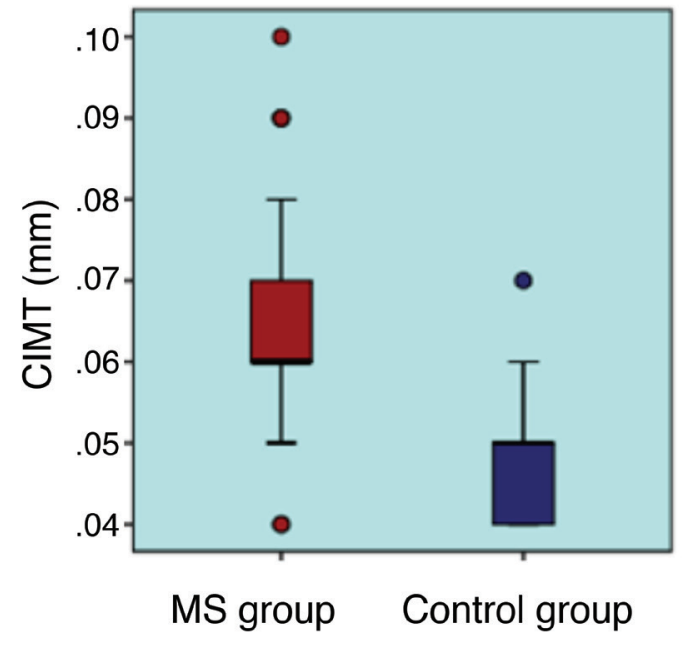

Figure 2. Carotid intima media thickness in groups CIMT: Carotid intima media thickness, MS: Metabolic syndrome healthy controls. Further, Cooke (9) reported that serum ADMA levels were associated with the development of cardiovascular diseases such as endothelial dysfunction, hypercholesterolemia, peripheral vascular disease, and hypertension.

Many studies have reported increased plasma ADMA concentrations in type 1 and type 2 diabetic patients. In a study of 40 uncomplicated type 1 diabetic patients, plasma ADMA levels were increased before the development of vascular complications (10). Another study, including 408 patients with type 1 diabetic nephropathy, suggested that increased ADMA levels contributed to diabetes-induced organ damage (11). However, there are other studies with contradicting results. In a population-based Framingham offspring study by Böger et al. (12), the mean ADMA levels were similar in diabetic and non-diabetic groups. Although, there was a positive correlation between ADMA levels and mortality in the non-diabetic group, no significant relationship was observed in the diabetic group. Päivä et al. (13) found decreased ADMA levels in type 2 diabetic patients and argued that this result may be due to increased glomerular filtration rate and poor glycemic control in their patients. In another study by Onat et al. (14), the relationships between serum ADMA levels and MS, type 2 DM, and coronary artery disease were investigated in 848 patients. Contrary to the expectations, serum ADMA levels were found to be low in patients with high fasting glucose, and they believed that this may be due to the leakage of some ADMA proteins, triggering an autoimmune response during the immune assays. In the study of Xiong et al. (15), it was found that adopting measures to target various metabolic abnormalities of MS and insulinsensitizing treatments, generally decreased ADMA levels. Wang et al. (5) found a decrease in plasma ADMA levels and improved flow-mediated dilatation of the brachial artery, 8 weeks after treatment, with rosiglitazone in non-diabetic patients with MS. A recent study found that plasma ADMA levels had a dynamic balance and that they did not correlate with cellular levels (16).

In our study, when compared with healthy controls, serum ADMA levels were found to be significantly lower and CIMT was found to be significantly higher, in patients. In our study, $86 \%$ of the patients in the MS group were diabetic, the median $\mathrm{HbA1c}$ levels were 9\% (5.6-13\%), and 29 patients received metformin. Serum ADMA levels were significantly lower in the metformin group than in the non-metformin group. In light of these findings, poor glycemic control-related interference or the use of metformin to break down insulin resistance may be one of the causes of low serum ADMA levels in the MS group. 
Table 3. The correlations between asymmetric dimethylarginine and metabolic syndrome components

\begin{tabular}{|c|c|c|c|c|c|c|c|c|}
\hline & & Age & BMI & Ws C & SBP & DBP & CRP & CIMT \\
\hline \multirow[t]{3}{*}{ ADMA } & $r$ & -0.112 & -0.428 & -0.351 & -0.330 & -0.217 & -0.335 & -0.261 \\
\hline & $p$ & 0.337 & $<0.001$ & 0.002 & 0.004 & 0.062 & 0.003 & 0.024 \\
\hline & & FBG & HbA1c & Tot C & LDL-C & HDL-C & TG & \\
\hline \multirow[t]{2}{*}{ ADMA } & $r$ & -0.421 & -0.361 & 0.017 & 0.155 & 0.247 & -0.316 & \\
\hline & $p$ & $<0.001$ & 0.001 & 0.884 & 0.186 & 0.033 & 0.006 & \\
\hline
\end{tabular}

Table 4. The correlations between carotid intima media thickness and metabolic syndrome components

\begin{tabular}{|l|l|l|l|l|l|l|l|}
\hline \multicolumn{2}{|l}{} & Age & BMI & Ws C & SBP & DBP & CRP \\
\hline & $r$ & 0.431 & 0.713 & 0.661 & 0.610 & 0.512 & 0.402 \\
\cline { 2 - 8 } & $p$ & $<0.001$ & $<0.001$ & $<0.001$ & $<0.001$ & $<0.001$ & $<0.001$ \\
\hline \multirow{2}{*}{ CIMT } & & FBG & HbA1C & Tot C & LDL-C & HDL-C & TG \\
\cline { 2 - 8 } & $p$ & 0.711 & 0.686 & 0.235 & 0.082 & -0.279 & 0.502 \\
\hline
\end{tabular}

BMI: Body-mass index, Ws C: Waist circumference, SBP; systolic blood pressure, DBP: Diastolic blood pressure, CRP: C-reactive protein, FBG: Fasting blood glucose, Tot C: Total cholesterol, LDL-C: Low-density lipoprotein-cholesterol, HDL-C: High-density lipoprotein-cholesterol, TG: Triglycerides, CIMT: Carotid intima media thickness

There are several limitations to our study. The first was the inadequate number of participants in the patient and control groups. Another was that most patients in the MS group had a diagnosis of DM and were receiving treatment for the same. If the newly diagnosed patients, who had no apparent DM and were not receiving any medications, were included in the study, the relationship between MS and serum ADMA could be considered to be free from medication effects and possible effects of poor glycemic control. Other limitations were the lack of insulin values and the absence of objective insulin resistance, although patients met the MS criteria.

\section{CONCLUSION}

In conclusion, in many studies, CIMT is accepted as an indicator of generalized atherosclerosis including that of the coronary arteries. MS is a cluster of diseases in which proatherosclerotic processes such as DM, hypertension, obesity, and hypercholesterolemia coexist. In our study, when increased CIMT values were considered as evidence for the presence of atherosclerosis in patients, the low levels of serum ADMA may be related to metformin therapy, poor glycemic control, and/or problems in the immune-assay.

\section{Ethics}

Ethics Committee Approval: Bursa Yüksek İhtisas Training and Research Hospital from which the ethics committee approval is obtained (23.10.2013/3).
Informed Consent: Consent form was filled out by all participants.

Peer-review: Externally and internally peer-reviewed.

\section{Authorship Contributions}

Surgical and Medical Practices: S.A., A.K., Concept: S.A., S.K., G.K., Design: S.A., A.K., G.K., Data Collection or Processing: S.A., A.K., Analysis or Interpretation: S.A., S.K., Literature Search: S.A., A.K., Writing: S.A.

Conflict of Interest: No conflict of interest was declared by the authors.

Financial Disclosure: The authors declared that this study received no financial support.

\section{REFERENCES}

1. Gören B, Fen T. The Metabolic Syndrome: Review. Türkiye Klinikleri J Med Sci 2008;28:686-96.

2. Ișıldak M, Sain Güven G, Gürlek A: Metabolik Sendrom ve İnsülin Direnci. Hacettepe Tıp dergisi 2004;35:96-9.

3. Kahaly GJ. Cardiovascular and atherogenic aspects of subclinical hypothyroidism. Thyroid 2000;10:665-79.

4. Kung AWC, Pang RWC, Janus ED. Elevated serum lipoprotein(a) in subclinical hypothyroidism. Clinic Endocrinology 1995;43:445-9.

5. Wang J, Sim AS, Wang XL, Salonikas C, Naidoo D, Wilcken DE, et al. Relations between plasma asymmetric dimethylarginine (ADMA) and risk factors for coronary disease. Atherosclerosis 2006;184:383-8. 
6. Altekin ER, Demir I, Başarıcı I, Yılmaz H: Karotis intima-media kalınlığının anjiyografik koroner arter hastalığı varlığı ve yaygınlığı ile ilișkisi. Türk Kardiyol Dern Ars 2007;35:90-6.

7. Vallance P, Leone A, Calver A, Collier J, Moncada S. Accumulation of an endogenous inhibitor of nitric oxide synthesis in chronic renal failure. Lancet 1992;339:572-5.

8. Böger RH, Bode-Böger SM, Szuba A, Tsao PS, Chan JR, Tangphao 0 et al. Assymetric dimethyl arginine (ADMA): a novel risk factor for endothelial dysfunction. Its role in hypercholesterolemia. Circulation 1998;98:1842 7.

9. Cooke JP. ADMA: its role in vascular disease. Vasc Med 2005;10:11-7.

10. Altinova AE, Arslan M, Sepici-Dincel A, Akturk M, Altan N, Toruner FB. Uncomplicated type 1 diabetes is associated with increased asymmetric dimethylarginine concentrations. J Clin Endocrinol Metab 2007;92:18815 .

11. Tarnow L, Hovind P, Teerlink T, Stehouwer CD, Parving HH. Elevated plasma asymmetric dimethylarginine as a marker of cardiovascular morbidity in early diabetic nephropathy in type 1 diabetes. Diabetes Care 2004;27:765-9.
12. Böger RH, Sullivan LM, Schwedhelm E, Wang TJ, Maas R, Benjamin EJ et al. Plasma Asymmetric Dimethylarginine and Incidence of Cardiovascular Disease and Death in the Community. Circulation 2009;119:1592-600.

13. Päivä H, Lehtimäki T, Laakso J, Ruokonen I, Rantalaiho V, Wirta 0 , et al. Plasma concentrations of asymmetric-dimethylarginine in type 2 diabetes associate with glycemic control and glomerular filtration rate but not with risk factors of vasculopathy. Metabolism 2003;52:303-7.

14. Onat A, Köroğlu B, Can G, Karagöz A, Yüksel M, Aydın M. Apparently "low" serum asymmetric dimethylarginine is associated with fasting glucose and tends toward association with type-2 diabetes. Anadolu Kardiyol Derg 2014;14:26-33.

15. Xiong Y, Fu YF, Fu SH, Zhou HH. Elevated levels of the serum endogenous inhibitor of nitric oxide synthase and metabolic control in rats with streptozotocin-induced diabetes. J Cardiovasc Pharmacol 2003;42:1916.

16. Davids M, Teerlink T. Plasma concentrations of arginine and asymmetric dimethylarginine do not reflect their intracellular concentrations in peripheral blood mononuclear cells. Metabolism 2013;62:1455-61. 